TEMAS EMERGENTES

\title{
Policía para la democracia: El caso de Carabineros de Chile
}

\author{
A police for democracy: The case of Carabineros de Chile
}

\author{
Felipe Abbott, (ID) Paz Pino (iD) y Renata Villamán (iD) \\ Universidad de Chile
}

\begin{abstract}
RESUMEN La policía es una institución seriamente cuestionada mundialmente por acciones violentas, discriminatorias y atentatorias de los derechos humanos. Se revisan antecedentes, iniciativas y recomendaciones insoslayables para la reconfiguración de una institución esencial para una sociedad democrática cuyo diseño y funcionamiento debe estar profundamente afianzado en el irrestricto compromiso con la protección de los derechos humanos.
\end{abstract}

PALABRAS CLAVE Historia de la policía, reforma policial, violaciones a los derechos humanos, estándares internacionales.

ABSTRACT Police is an institution severely questioned worldwide due to violent, discriminatory and against human rights behavior. Unavoidable records, initiatives and recommendations are reviewed regarding the reconfiguration of an essential institution for a democratic society whose design and operation must be deeply clinched in the unconditional commitment to human rights protection.

KEYWORDS Police history, police reform, human rights violations, international standards.

\section{Introducción: La policía, institución indispensable de la organización del Estado}

El 18 de octubre de 2019 marcó el inicio del «estallido social» y, con ello, la perpetración de una serie de violaciones masivas y sistemáticas a los derechos humanos en contra de manifestantes y adherentes a las demandas sociales. 
En poco más de un año, cuatro ministros han pasado por el Ministerio del Interior y Seguridad Pública, mientras que sus salidas se han llevado a cabo entre ecos y críticas por las violaciones a los derechos humanos y otros cuestionamientos relativos a la mantención del orden público, función que se encuentra radicada en esta cartera. Por otro lado, un Cuerpo de Carabineros respaldado por la autoridad civil sigue casi inmutable en su actuar mientras se acumulan investigaciones penales y administrativas, críticas públicas y recomendaciones de organismos internacionales.

Dicho contexto, que a simple vista parece inexplicable, tiene asidero en la tradición que esta institución policial ha desplegado desde la imposición de la dictadura cívico-militar de Augusto Pinochet, y que se ha mantenido desde el retorno a la democracia, existiendo una pugna entre un modelo de policía con sumisión al orden civil democrático, y una policía con cierta autonomía de este orden, con características eminentemente militares.

Para comprender más cabalmente cómo se ha llegado a este escenario y qué hacer en él, se hace imprescindible una reflexión previa. La policía surge de la mano de la estructura moderna del Estado, cuando en él comienzan no solo a hacerse visibles la estratificación convencional de clases y el delineamiento de fuerzas políticas, sino que cuando comienza a vislumbrarse que tales fuerzas políticas buscan dotarse de posiciones reconocibles respecto al acceso al poder de modo institucional. Así, la proscripción del uso de la fuerza estatal a favor de una facción particular sienta las bases de la política, que es entonces cuando se hace visible la fuerza llamada a mantener el orden, conocida más contemporáneamente como policía. De este modo, no hay en definitiva Estado en que no exista un ente con poder suficiente para cautelar la seguridad interior, velar por la vigencia de las normas dictadas por la autoridad, además de procurar prevenir y reprimir la delincuencia protegiendo -o haciendo como que lo hace - a la población de atentados o amenazas a su vida, su integridad física, su propiedad u otros derechos. Este proceso sin embargo albergará con frecuencia elementos propios del estadio evolutivo más primitivo, en tanto las fuerzas de orden, instrumentalizadas, constituyan aún la representación del mero poder de una facción política sobre otra.

Las policías surgen así como instrumentos de clase, rasgo paradójico y regresivo que se convierte en recurrente, haciendo que los cuadros generales de las policías se alimenten de efectivos de los mismos entornos de los grupos a quienes mayoritariamente persiguen. Dichos efectivos, en la expectativa de una movilidad social a medias que la vida uniformada ofrece, se sumergen en la adscripción incondicional, por la vía del adoctrinamiento, a los valores de la autoridad que se pretende representar. En consecuencia, incluso de resultar ser un poder déspota y brutal, su obediencia y disciplina los pone en la aceptación sin cuestionamientos de la orden de violentar o de vulnerar.

La policía latinoamericana bebe de la tradición de los modelos de las que es co- 
lonia, a partir del aporte ibérico, pero extendiéndose rápidamente más allá: el desarrollo de las primeras instituciones policiales americanas se verifica de la mano de la aparición de los primeros modelos propiamente tales de policía en Europa: el inglés, el francés o el prusiano. En Chile destaca la presencia de rasgos del modelo español e italiano, tanto en su carácter militar como centralizado y tradicional, coherente con dos países de marcada tradición conservadora latifundista que se dotaron de policías orientadas hacia la ruralidad, el resguardo de los intereses propietarios y frente al alzamiento del campesinado y la mano de obra rústica. A medida que las excolonias forjan una identidad nacional y una estructura estatal, viene la necesidad de consolidar también un modelo de policía que deje atrás la precariedad de la simple extensión de competencias a fuerzas militares o milicias que, por el solo hecho de estar armadas, pudieran juzgarse a priori como aptas para la labor policial. Sin embargo, el defender el estatus se hace insostenible con la necesidad de robustecer el diseño y consolidación de un Estado moderno, incluyendo la disponibilidad de instrumentos de control de la población y el territorio adecuados a su progresiva complejización.

Se produce una sofisticación de los conflictos, que pasan de nacionales a cívicos, en que el enemigo extranjero - antiguo conquistador - o la identidad nacional ajena-disputadora de límites, cede terreno y se mezcla con facciones de poder interno, que oportunistamente y de modo más o menos solapado pretenden llevar a cabo maniobras que les granjee el paso a espacios de mayor influencia, pasando por los cambios que presenta la fisonomía de las formas de vida y la irrupción de la criminalidad y la delincuencia convencionales como señales de progreso, demandando respuestas institucionales que determinan los contornos de esta institución conocida como «policía». Así, se desarrolla un tránsito desde ser simples secciones de fuerzas militares abocadas a la persecución del bandidaje, o contingentes armados desplegados en territorios rurales, aislados o fronterizos, hasta la constitución de cuerpos desplegados en las ciudades o incluso identificados con determinados sectores de ellas, y sus funciones determinadas por las características de tales sectores, hasta la irrupción de la ciencia positiva con la aparición de la especialización, de las policías científicas, judiciales o de investigación. Las policías son también el rostro del cambio del Estado, desde sus inicios poscoloniales hasta sus primeras pretensiones modernizadoras.

Sin embargo, aun en medio de procesos de consolidación de estos cambios (por ejemplo, la separación de la policía de sus antecesores formalmente militares, o la creación de las primeras unidades de policías de investigación en Chile, entre las décadas de 1920 y 1930), perviven algunos de sus rasgos primitivos: la validación de su uso como herramienta de control político y su instrumentalización por parte del poder, llevado a cabo tanto abiertamente por medio de efectivos de uniforme y a la vista del público, como por individuos de civil, en funciones de policía secreta.

Así las cosas, la policía latinoamericana llega al último tercio del siglo XX investida de las características, fisonomía y atribuciones clásicas de estos organismos: or- 
ganizada, jerárquica y especializada, mayoritariamente unitaria, fundamentalmente militarizada, ocupada de la custodia del orden público y del cumplimiento de la ley, como su brazo armado presto a su auxilio para la efectividad de su mandato. Según sea el caso, el diseño organizacional comprende espacios de cooperación multiagencias para la vigilancia de fronteras terrestres, marítimas o aéreas, labores de rescate y auxilio ante emergencias (incluida la búsqueda de personas extraviadas) o el cuidado de personalidades públicas y la guardia y cuidado de edificios o infraestructura.

\section{Carabineros de Chile: Desarrollo histórico y doctrina}

\section{Orígenes y fundación}

En Chile, la fuente de la policía es la organización militar; sin embargo, en los albores de la República los institutos policiales fueron siempre alojados al alero del poder político, esto es $-\mathrm{y}$ en orden jerárquico vertical- dependientes de la Presidencia de la República, el Ministerio del Interior y, por extensión, de los intendentes y gobernadores. En consecuencia, se entendía su mandato esencialmente civil y alejado de los ministerios de Guerra o de Defensa y, por ende, de las Fuerzas Militares. A nivel territorial, su despliegue los radicaba en el orden municipal o de las comunas correspondientes, cuando se tratara de funciones desempeñadas en núcleos urbanos.

Entre sus funciones, que hoy se describen diferenciando las actividades preventivas de las investigativas, hacia mediados del siglo XIX ya se esbozaban los primeros indicios de esta segregación funcional cuando se establecían los primeros cuerpos de policía y se les encomendaba tanto labores de seguridad pública, de aseo y de decoro o custodia de las buenas costumbres, como también de vigilancia de reuniones sediciosas, la persecución del ultraje del culto o la represión del contrabando. Ya a finales del mismo siglo, las normativas pertinentes consideraron aplicable la diferenciación entre funciones de orden (aseo, tránsito y desplazamiento callejeros, por ejemplo) y de seguridad (represión de la criminalidad común). En este último caso, progresivamente se va incluyendo la represión del delito político y surgiendo la figura de la policía secreta.

Los institutos policiales se organizan en torno a la protección de la propiedad y la cautela de los intereses económicos locales, que muchas veces constituían incluso la forma en que se dotaban de su respectivo gobierno (con juntas o consejos que supervisaban su acción integrados por los más importantes contribuyentes, o eran derechamente organizaciones creadas para la protección de los gremios y su actividad extractiva, como en el caso de zonas mineras). Con el tiempo, tal protección se fue extendiendo más allá, alcanzando poco a poco la infraestructura y el espacio público, como bosques, aguas, telégrafos y ferrocarriles.

Si bien las policías nacionales en su camino hacia la consolidación transitaron por la municipalización, este modelo no fue exitoso, consecuencia de la gran disparidad 
en la dotación de recursos entre las comunas, lo que llevó a que muchas solo pudieran contar con algo parecido a una policía recibiendo ayudas y subsidios del Gobierno central, o en otros casos por la instrumentalización de los cuerpos policiales por las autoridades locales, lo que redundó en su transformación en milicias caudillistas. A todo lo anterior no ayudó el hecho de que, si había menester, la autoridad central podía solicitar el envío y disposición de tales cuerpos policiales para su servicio en la capital, lo que redundó más bien en el fortalecimiento de las policías de Santiago y Valparaíso antes de que prosperaran los de provincias más alejadas. Este modelo atomizado y bajo el control de autoridades locales también mostró debilidades para mantener a las policías ajenas a conductas de corrupción, las que llegaron a hacer crisis a principios del siglo XX, exigiéndose entonces ya una reforma a las policías municipales, reclamando un cuerpo unificado.

Lo anterior se vio agravado por la evidente falta de eficiencia del accionar de las policías municipales, multiplicados los factores ya expuestos con la escasa preparación de sus efectivos, la cuestionable incorporación de exconvictos en sus filas o el fenómeno del bandolerismo posterior a la desmovilización de las tropas de la guerra del Pacífico, todo lo cual obligó progresivamente al involucramiento de unidades militares en funciones de custodia y vigilancia, ya sea de los campos como del ferrocarril y sus estaciones.

El inicio del siglo XX trajo consigo desafíos que no estaban al alcance de las policías municipales, lo que significó que fuerzas militares se involucraran cada vez más en tareas de orden público. De este modo se conformaron progresivamente unidades con contingente desmovilizado del ejército, como fue el caso de los gendarmes de las colonias, que operaron hacia la zona sur y la Araucanía al mando del veterano de la guerra del Pacífico Hernán Triziano, o directamente por la destinación de contingentes militares a tareas policiales, con lo que fueron desplegadas a lo largo del territorio nacional fuerzas militares con ese propósito. Este último es el caso de la creación del regimiento de gendarmes, que luego devino en regimiento y cuerpo de Carabineros. Este cuerpo fue creciendo y asumiendo progresivamente más tareas, como la custodia de las fronteras y el servicio de aduanas o ferrocarriles.

La efervescencia social de su primera década implicó que estas fuerzas armadas se vieran involucradas en actos brutales de represión, en Valparaíso (1903), Santiago (1905), Iquique (1907) o posteriormente en oficinas salitreras como Marusia o La Coruña (1925). Sin embargo, el repliegue de las fuerzas militares de funciones ajenas no eliminó la injerencia militar en la policía, la que estuvo durante mucho tiempo encabezada por jefes castrenses.

De forma posterior, los episodios de violencia y abuso de la fuerza por parte de la autoridad cambiaron de protagonista, pasando a manos de la nueva policía de la época, Carabineros de Chile. Este se «inauguró» con la matanza de Ránquil (1934) y continuó con las del Seguro Obrero (1938), Plaza Bulnes (1946), Pampa Irigoin (1962) 
hasta el año 1973, cuando en el contexto ya de la dictadura militar, Carabineros de Chile lleva a cabo en septiembre mismo la masacre de Laja.

Carabineros de Chile nació el 27 de abril de 1927, completamente tributario de la intervención militar de 1924 que derrocó a Arturo Alessandri, y bajo la directa mirada del entonces coronel de Ejército, ministro del Interior y de Guerra Carlos Ibáñez del Campo.

Su carácter militar no solo vendría dado por el hecho de surgir de la fusión de las policías fiscales con el cuerpo de Carabineros del Ejército, sino que derivada de la disposición de su ley orgánica del mismo año, que establecía que si bien su tuición quedaba radicada principalmente en el Ministerio del Interior, este podía trasladarla al de Guerra para que esta policía quedara a disposición de aquel, así como de la posibilidad de incorporar efectivos militares activos a las filas del cuerpo policial para prestar excepcionalmente servicios; por último, se puede consignar que se extendía a este cuerpo policial el fuero de la justicia militar en todos sus órdenes. Este rasgo distintivo también se manifestó doctrinariamente, compartiendo Carabineros de Chile la influencia prusiana que caracterizó al Ejército, influencia que fue a medias morigerada por cierta influencia del modelo policial italiano.

\section{La policía y la represión política en dictadura}

El extendido escenario de dictaduras en América Latina hacia las últimas décadas del siglo reconfiguró profundamente este esquema, insertando en lo más profundo de las policías un elemento nuevo: la doctrina de la seguridad interior y su enemigo interno.

Conforme a esta doctrina, las policías, conjuntamente con las Fuerzas Armadas, se sumaron a la estrategia de persecución y exterminio de la disidencia política, para lo cual adecuaron su organización conforme al nuevo rol impuesto: el desarrollo de la inteligencia política, que implicaba el fortalecimiento del perfil de policía política secreta, la sistematización de técnicas de interrogatorio (incluida la tortura), el distanciamiento de la ciudadanía, un retroceso de los límites del diálogo civil hasta la frontera de la simple fuerza de la autoridad armada y del amedrentamiento, y el abandono de toda doctrina de sujeción al poder civil y al imperio de la ley. Con ello se consolidaba un instrumento de represión que resultaba funcional a la lógica del allanamiento masivo, la violencia contra la libertad de expresión, la detención ilegal, la tortura, el asesinato selectivo, el genocidio y la desaparición de personas.

La escasa respuesta de otros sectores de la institucionalidad, menos intervenidos pero igualmente obsecuentes, como es el caso del Poder Judicial, llevó a las policías a fortalecer sus sentimientos de impunidad, lo que constituyó la base para el incremento de la brutalidad temeraria.

Carabineros de Chile se suma a la conjura golpista de 1973, cuestión que le granjea el acceso al Gobierno de facto, integrándose a la Junta de Gobierno al lado del Ejérci- 
to, la Armada y la Fuerza Aérea. Ello se traduce, en consecuencia, en la incorporación de oficiales de Carabineros de Chile a la administración del Estado, en las más diversas funciones y organismos públicos.

Una integración al Gobierno de facto especialmente dramática la constituye la suma de miembros de Carabineros de Chile a los organismos dedicados a la represión política, esto es, la persecución, captura, tortura, asesinato y desaparecimiento de personas identificadas como disidentes o contrarios al régimen. Así, funcionarios policiales integraron la DINA, la CNI, el Comando Conjunto, así como los comandos y servicios regionales de inteligencia, además de disponer Carabineros del funcionamiento de un organismo propio, la Dicomcar. El accionar de todas estas agencias superó el control de cualquier instancia judicial, respaldadas por un Gobierno que hizo caso omiso a las recriminaciones, informes, recomendaciones o demandas internacionales relativas a las denuncias sobre las graves violaciones a los derechos humanos que ocurrían en el país y de que se tenía noticia en el mundo.

Algunos casos superaron incluso la barrera de la oscura connivencia con la justicia y llevaron a investigaciones judiciales con consecuencias personales e institucionales, de los cuales el más emblemático fue el denominado caso «Degollados», que tiene como protagonistas precisamente a agentes de la policía uniformada.

El caso «Degollados» representa una sima abisal del proceso de descomposición humana derivado de las actividades represoras de la dictadura cívico-militar. En él, a principios del año 1985, miembros de la Dirección de Comunicaciones de Carabineros (Dicomcar), la agencia de inteligencia de la propia policía uniformada, secuestran, torturan y dan muerte a tres profesionales y dirigentes de izquierda, José Manuel Parada, Santiago Nattino y Manuel Guerrero Ceballos.

Si bien inicialmente los jerarcas del régimen declararon, como era la tónica en aquella época, que las muertes eran producto de rencillas o ajustes de cuentas al interior de la orgánica comunista, el ministro en visita extraordinario designado para llevar a cabo la investigación, José Cánovas Robles, dio rápida cuenta de la trama policial tras el crimen, identificando y procesando a diversos oficiales y suboficiales de la agencia de inteligencia, así como a pilotos de la prefectura aeropolicial que habían participado en la operación que permitió el secuestro de dos de los tres asesinados mientras se encontraban a las afueras de un colegio en horas de la mañana.

La resolución judicial dictada contra más de una docena de efectivos policiales, incluidos altos rangos a la cabeza de la Dicomcar, su jefatura de asuntos internos o la cabeza del Grupo de Operaciones Especiales (Gope), provocó la renuncia del general director de Carabineros y miembro de la Junta Militar de Gobierno, César Mendoza Durán, quién detentaba tales cargos desde 1973, y que fue reemplazado por el general Rodolfo Stange Oelckers. El caso siguió su curso luego de iniciada la transición democrática, dictándose sentencia definitiva en 1994 por el ministro Milton Juica. 
Es de ese modo que la policía uniformada de Carabineros de Chile recibe la llegada de la democracia en 1990.

\section{Carabineros de Chile y la normalización democrática}

El régimen democrático impuso dos desafíos adaptativos significativos a las policías, en el ámbito específico de sus atribuciones. Por un lado, una estrategia de progresiva incorporación de una perspectiva comunitaria, de gestión y modernización de los mecanismos de evaluación de las tareas preventivas e investigativas, que en Carabineros de Chile fue conocido como «Plan Cuadrante». Este plan suponía la vinculación de los medios policiales con las evaluaciones de demanda de tales recursos, uniendo tecnología, procedimientos, rendición de cuentas y cercanía con la comunidad. Las evaluaciones de esta estrategia, a veinte años de su puesta en marcha, revela una deficiente implementación y un decreciente rendimiento en los resultados esperados.

Junto a él, las policías han debido ajustarse a un escenario a medias externo, cual es la entrada en vigor de un nuevo régimen procesal, que supuso la incorporación al sistema de administración de justicia penal de actores tan relevantes como el Ministerio Público, la Defensoría Penal Pública o el rediseño de los tribunales competentes, con lo que surgieron los Juzgados de Garantías y los Tribunales Orales en lo Penal. Ello asimismo implicó una redefinición de facultades y prerrogativas, así como el establecimiento de nuevos vínculos de dependencia funcional, especialmente en lo que respecta a la persecución penal de los delitos y concretamente respecto de tareas investigativas. Son diversas las evidencias que dan cuenta de brechas en el comportamiento óptimo esperable en el trabajo policial, relativas al trato a las víctimas y la observancia irrestricta de los derechos de los y las imputadas y los principios del debido proceso.

Por otro lado, el tránsito progresivo hacia la normalización democrática e institucional no trajo consigo necesariamente una consolidación de un modelo policial alejado por completo de la violencia desmedida y la ausencia de rendición de cuentas ante la autoridad civil. Hay, lamentablemente, un largo historial de hechos que distan en definitiva de ser aislados. Solo a modo de resumen, podemos consignar distintas dimensiones de problemas, que involucran muertes de civiles por acción policial o déficits severos de control interno y externo institucional que han ocasionado que el capital de confianza en la policía uniformada nacional se haya ido progresivamente deteriorando.

\section{Muertes por acción policial}

La acción policial, haciendo uso de armamento letal, tiene entre su tristes registros los casos de la balacera de Apoquindo (1993), en el contexto de un asalto a una sucursal bancaria ubicada en un concurrido centro comercial, donde se produjeron 
numerosas víctimas inocentes entre civiles atrapados el fuego cruzado; o los casos de Claudia López (1998) y Manuel Gutiérrez (2011), víctimas de funcionarios de Carabineros en circunstancias en que no hubo justificación alguna al uso de armas de fuego e, incluso, se procuró entorpecer las investigaciones conducentes a aclarar el hecho e identificar a los responsables.

Un historial más triste aún es el conflicto intercultural que se desarrolla principalmente en las regiones de la Araucanía y el Biobío. En él, y en el marco de un enfrentamiento marcado por la militarización de un territorio y la pobreza de los recursos políticos puestos al servicio del diálogo y la paz, fuerzas policiales cada vez más fuertemente armadas han dado muerte a numerosos miembros del pueblo mapuche o asociados a su causa, entre otros, Alex Lemún (2002) - caso que dio origen a una causa ante la Corte IDH-, Juan Collihuin (2006), Matías Catrileo (2008), Johnny Cariqueo (2008) y Jaime Mendoza Collío (2009). Podemos subrayar el caso de Brandon Hernández Huentecol (2016), que trajo consigo fuertes recriminaciones internacionales (Unicef) sobre el accionar de Carabineros de Chile, en el contexto del conflicto en la Araucanía y el tratamiento de niños, niñas y adolescentes, y originó un informe de una red de organizaciones no gubernamentales protectoras de derechos, y la participación de la CIDH. Para concluir este apretado resumen, destaca el caso del asesinato del comunero Camilo Catrillanca (2018), en que se dio muerte por un disparo al joven mapuche en el marco de un pretendido operativo por el robo de un vehículo, llevado a cabo por un comando especialmente entrenado en guerra de guerrillas en el extranjero y desplegado en la región. En dicho operativo se ejecutaron diversas acciones para encubrir las circunstancias en que el hecho se había producido y facilitar la impunidad de los intervinientes, incluidos los mandos de las unidades involucradas.

\section{Disciplina institucional}

Carabineros asimismo presenta un severo déficit de rendición de cuentas y subordinación efectiva al poder político civil, del que supuestamente depende. Evidencia de lo anterior lo constituye, en primer lugar, el corolario del ya citado caso «Degollados». En 1994, aún frescas en la memoria las violaciones a los derechos humanos perpetradas por agentes del Estado en dictadura, y con el país en vías de normalización democrática, el ministro Milton Juica cerraba el caso y dictaba sentencia contra los involucrados, y además extendía las imputaciones al, a la sazón, general director Rodolfo Stange. En ese contexto, el presidente de la República de la época, Eduardo Frei Ruiz-Tagle, y conforme la legislación vigente, le solicitó la renuncia al general Stange quién, en respuesta, simplemente dijo: «Yo no renuncio». ${ }^{1}$ Ese amargo recor-

1. El general Rodolfo Stange se acogió a retiro en 1995. En 1997, postuló y resultó electo para un escaño al Senado con el respaldo de la Unión Demócrata Independiente, partido político de la derecha chilena, 
datorio del precario estado de cosas de la democracia de que se disponía entonces, condujo de algún modo a la reforma constitucional de 2005, reforma que entre otras cosas vino a modificar el estatuto de inamovilidad de los comandantes en jefe de las Fuerzas Armadas, de Orden y Seguridad. Ella representa una dramática respuesta a la demanda de democratización del diseño de las relaciones cívico-militares, esfuerzos que pretendieron reforzarse con el cambio en la dependencia de las fuerzas de orden y seguridad, trasladándola al Ministerio del Interior, con su consiguiente reforma orgánica, que implicó también la creación de la Subsecretaría de Prevención del Delito.

\section{Otros problemas}

Por si lo anterior fuera poco, la institución ha exhibido serios problemas internos relacionados con el trato a sus propios miembros, principalmente suboficialidad, acusaciones de influencias indebidas a favor de parientes por parte de un general director en ejercicio, filtraciones de información producto de ciberataques (que dan cuenta de la vulnerabilidad de sus sistemas, considerando la sensibilidad de la información en manos de la policía), hasta investigaciones por operaciones financieras que constituirían enormes fraudes con fondos fiscales (uno que involucra a la Mutual de Carabineros, cuya investigación se inició en 2018; otra, el fraude más grande del que se tenga registro hasta ahora, investigación en desarrollo conocida como «Pacogate», que data de 2016).

Más grave resulta, sin embargo, el denominado caso «Huracán» (2017), en que personal de la unidad especializada de inteligencia dedicada a investigaciones sensibles en el marco del conflicto en la Araucanía creó un escenario favorable para la imputación de delitos graves, su posterior detención e ingreso en prisión preventiva de un importante número de líderes mapuches, presentando evidencia no solo adulterada, sino completamente artificial, concebida de la nada con el único efecto de justificar el operativo policial, en un hecho que puso a prueba las bases mismas del sistema procesal penal vigente. El progresivo esclarecimiento de los hechos y la identificación de responsabilidades no solo afectó a Carabineros de Chile, sino a toda la administración de justicia, habida cuenta de que había sido embaucada por un montaje policial respaldado por el Ministerio Público y los tribunales que, en su oportunidad y ante la evidencia exhibida, habían dado curso a las solicitudes de prisión preventiva solicitadas contra los líderes del pueblo indígena. El hecho también afectó las relaciones internacionales, ya que se pretendía acusar a los líderes mapuches de la internación de armamento desde Argentina, situación que obligó a autoridades del Poder Ejecutivo a tomar contacto con sus homólogos de ese país para compartir información y eventualmente coordinar acciones.

hasta 2006. Aunque enfrentó interrogatorios por otras causas de derechos humanos, todos los cargos fueron en definitiva desestimados. 
Estos hechos acarrearon finalmente la salida del general director de la institución de la época, Bruno Villalobos, y la reestructuración de la institución luego de la salida de una quincena de generales en la renovación del alto mando subsecuente. El general Hermes Soto sucedió al general Villalobos en la dirección de Carabineros de Chile. El general Soto, por su parte, tuvo que abandonar el mando de la institución como consecuencia del ya mencionado caso Catrillanca.

No resulta entonces sorprendente que reformar Carabineros de Chile sea hasta el momento un proyecto provisionalmente fallido.

\section{Las reformas: De la sujeción a la autoridad civil a la modernización}

\section{Policía militar y sujeción a la autoridad civil: Las primeras iniciativas}

En efecto, no obstante que la función constitucional de Carabineros de Chile radica en funciones de orden y seguridad internos, consistentes en constituir la fuerza pública, dar eficacia al derecho, garantizar el orden público y encargarse de la seguridad pública interior (artículo 101 de la Constitución), la misma constitución reconoce a Carabineros con la calidad de un cuerpo armado, al punto que en el artículo 2 de la Ley Orgánica Constitucional de Carabineros (Ley 18.961) se señala que, «Carabineros de Chile como cuerpo policial armado es esencialmente obediente, no deliberante, profesional, jerarquizado y disciplinado y su personal estará sometido a las normas básicas establecidas en la presente ley orgánica, su estatuto, Código de Justicia Militar y reglamentación interna». De esta manera, contando con una policía reconocida como cuerpo armado y sometida al Código de Justicia Militar, la pregunta que se desprende a continuación es: ¿a quién rinde cuentas Carabineros de Chile?

La redacción original de la Constitución de 1980 consagraba a Carabineros de Chile como una fuerza de orden y seguridad pública, señalando en su artículo 90 que «Carabineros se integrará, además, con las Fuerzas Armadas en la misión de garantizar el orden institucional de la República», y dependiente del Ministerio de Defensa Nacional. A la hora de realizar este análisis, no hay que perder de vista que una de las principales pugnas que Chile vivió durante el período de la transición fue la que enfrentó el nuevo orden democrático contra el poder fáctico, político y económico ostentado por las Fuerzas Armadas, que mantenían una estructura de poder e idiosincrasia en pugna por mantenerse autónomas e incólumes ante el poder civil. En este sentido, la disposición orgánica de Carabineros, tanto normativa como fáctica, juegan un rol principal.

A este respecto, la reforma constitucional de 2005 vino a generar cambios fundamentales en dicho modelo. Por un lado, se restaron límites al ejercicio de la facultad ostentada por el presidente de la República, consistente en llamar a retiro a los comandantes en jefe de las Fuerzas Armadas o al general director de Carabineros, pues en su redacción original la Constitución permitía el ejercicio de esta potestad 
solo en casos calificados y contando con el acuerdo del criticado Consejo de Seguridad Nacional (Cosena). Por otro lado, se modificó el artículo 90, derivando en el contenido del actual artículo 101, en que se cambia la dependencia de Carabineros, desde el Ministerio de Defensa al «Ministerio encargado de la Seguridad Pública». En adición, un mes después de dicha reforma, por medio del Decreto 100 del Ministerio Secretaría General de la Presidencia, se dictó la decimoséptima disposición transitoria de la Constitución, en virtud de la cual «las Fuerzas de Orden y Seguridad Pública seguirán siendo dependientes del Ministerio encargado de la Defensa Nacional hasta que se dicte la nueva ley que cree el Ministerio encargado de la Seguridad Pública».

Este tránsito en la dependencia de la institución resulta esencial, al ser un primer paso en el proceso de extraer a Carabineros su lógica de funcionamiento y autonomía propias de la dictadura, separándolo orgánicamente de las Fuerzas Armadas.

En este marco, en junio del año 2006, la presidenta Michelle Bachelet presentó el proyecto de ley de la actual Ley 20.502. El objetivo de este proyecto era la creación del Ministerio de Seguridad Pública y del Servicio Nacional para la Prevención del Consumo y Tráfico de Drogas, como parte del Programa propuesto en su campaña para los primeros cien días de su mandato.

En el mensaje de la presidenta al Senado, ${ }^{2}$ Bachelet asevera que entre los fundamentos de dicho proyecto se encuentra, por un lado, la discusión respecto a la seguridad pública, y, por otro, el antecedente normativo de la reforma constitucional de 2005.

Durante la discusión parlamentaria de la ya citada reforma constitucional, se desarrolló un debate respecto a cuál debería ser la forma de organización de las tareas de seguridad pública, considerando las dificultades que para ello tenía el que Carabineros de Chile y la Policía de Investigaciones dependieran del Ministerio de Defensa, pero al mismo tiempo llevaran a cabo funciones bajo la dirección del Ministerio del Interior. ${ }^{3}$ El Gobierno de ese entonces, junto con los parlamentarios, concordaron que la mejor solución sería la creación de un Ministerio de Seguridad Pública del cual dependieran los cuerpos policiales, y así se estableció en los ya mencionados artículo 101 y decimoséptima disposición transitoria de la Constitución.

El proyecto de ley definía el nuevo Ministerio de Seguridad Pública y radicaba en él la dependencia de las Fuerzas de Orden y Seguridad. Durante su discusión, y en consecuencia, en la determinación de la dependencia de las Fuerzas Armadas, resultó de fundamental relevancia el posicionamiento y entendimiento del binomio orden público-seguridad pública.

En este marco, inicialmente Bachelet decide mantener el orden público a cargo

2. Mensaje 161-354, del 15 de junio de 2006.

3. Informe de la Comisión de Constitución, legislación, justicia y reglamento del Senado, sesión 60, 16 de octubre de 2007, Legislatura 355, Boletín 4.248-05. 
del Ministerio de Interior. Entre los argumentos para esta decisión, Bachelet afirmó que «no resultaría apropiado que los problemas de orden público fueran abordados con criterios que son más propios de la prevención o el control de la delincuencia». ${ }^{4}$ En esta línea, destaca que «la mayoría de las actividades que atentan contra el orden público no constituyen delitos y no es conveniente enfrentarlas como si lo fueran; por otra parte, los delitos, por regla general, no implican una amenaza actual al orden público». ${ }^{5}$

Pese a ello, durante la tramitación de este proyecto de ley, el Ejecutivo presentó una serie de indicaciones que contradicen esta idea inicial. Entre ellas, resulta de particular importancia la indicación sustitutiva que hizo llegar a la Comisión de Constitución del Senado mediante Oficio $496-354,{ }^{6}$ en que se retracta de la creación de un ministerio encargado exclusivamente de la seguridad pública, de forma tal de radicar estas funciones en el Ministerio del Interior, pretendiendo reformarlo.

El ministro del Interior, Belisario Velasco, explicó a la Comisión de Constitución del Senado que, recogiendo las inquietudes planteadas en los debates al interior de la Comisión, así como las experiencias nacionales e internacionales, se decidió retroceder en la idea de un Ministerio de Seguridad Pública y, en reemplazo, proponer una Subsecretaría de Seguridad Pública dentro del Ministerio del Interior.?

A partir de los argumentos del Ejecutivo, y de la discusión legislativa, se pueden concluir diversos motivos que habrían respaldado esta decisión. Por una parte, es posible hablar de un argumento orgánico, que busca evitar la doble dependencia de las instituciones policiales, las cuales, bajo los supuestos iniciales del proyecto y producto de la función policial misma, quedarían tanto bajo dependencia del Ministerio de Interior como del Ministerio de Seguridad Pública. Sin embargo, en otros términos, encontramos un argumento sustantivo relativo a la concepción que se mantiene respecto del binomio orden público y seguridad pública, opuesto al presentado por la presidenta en el mensaje del proyecto. El ministro Velasco planteó que tener el orden público a cargo del Ministerio del Interior mientras otro ministerio se encarga de la parte delictual, «además de ineficiente, es confusa, por cuanto nadie puede determinar dónde termina el orden público y empieza el delito». ${ }^{8}$

El trámite de este proyecto finalizó en 2011, culminando en la promulgación de la Ley 20.502, que crea el Ministerio del Interior y Seguridad Pública, radicando a Carabineros de Chile en esta cartera.

4. Historia de la Ley 20.502, Biblioteca del Congreso Nacional de Chile, p. 11, disponible en https:// bit.ly/3kURxiD.

5. Historia de la Ley 20.502, p. 11.

6. Mensaje ejecutivo, Oficio 496-354, 22 de noviembre de 2006.

7. Historia de la Ley 20.502, p. 132.

8. Historia de la Ley 20.502, p. 133. 
Esta reforma marca la pauta en lo que será el desarrollo de la institución policial en los años siguientes. Si bien viene en significar una concreción orgánica de la separación de Carabineros y las Fuerzas Armadas, en la práctica estas reformas no han dado cuenta de una real sumisión de Carabineros de Chile al poder civil, ya que es aún una policía altamente militarizada, con una amplia autonomía y escasa transparencia, además de una idiosincrasia casi sin variaciones desde el regreso a la democracia.

Por otro lado, a la luz de la realidad actual, esta reforma deja abiertos cuestionamientos relativos a la conveniencia de mantener a Carabineros de Chile bajo las órdenes de un ministerio eminentemente político, en que las funciones de orden y seguridad pública se entremezclan, situación que da cuenta de la persistencia en la criminalización de la protesta social o cualquier actividad que implique algún tipo de alteración al orden público, mientras que la sujeción de Carabineros a un ministerio encargado exclusivamente de la seguridad pública será una propuesta que renacerá luego de la crisis de derechos humanos sufrida en Chile durante el último año.

\section{El estallido social y sus consecuencias}

Ocurridos los hechos de octubre de 2019 en adelante, diversos organismos de derechos humanos, el Instituto Nacional de Derechos Humanos y la sociedad civil activa comenzaron a denunciar las graves violaciones a los derechos humanos perpetradas con ocasión de la acción de efectivos policiales y militares en funciones de resguardo del orden público. Ellas dieron lugar a visitas, audiencias públicas e informes que presentaron información sistematizada relativa a las víctimas y circunstancias de los hechos, así como abundantes sugerencias y recomendaciones dirigidas a detener la ocurrencia de tales hechos y prevenir su verificación futura. Los poderes Legislativo y Ejecutivo, por su parte, generaron también instancias ad hoc para la formulación de propuestas de reforma a Carabineros de Chile. Del conjunto de tales recomendaciones podemos obtener la siguiente relación de aspectos fundamentales, principios y estándares.

\section{Estándares para el control del orden público}

El derecho internacional de los derechos humanos ha fijado una serie de recomendaciones y principios en miras a guiar el desarrollo de cuerpos policiales acordes a los estándares internacionales de derechos humanos y de una policía democrática. En este sentido, el manual «Normativa y práctica de los derechos humanos para la Policía», de la Oficina del Alto Comisionado de las Naciones Unidas para los Derechos Humanos (ACNUDH, 2003), dispone que las policías deben adoptar una política global de derechos humanos para su organización, incorporar las normas de dere- 
chos humanos al reglamento interior de la policía, capacitar a sus funcionarios en la materia y cooperar con las organizaciones nacionales e internacionales de derechos humanos (ACNUDH, 2003: 1-2). Asimismo, dispone que en una democracia la policía debe ser un órgano independiente, parte del Ejecutivo, y que debe actuar bajo la dirección de los tribunales y estar sujeta a sus órdenes (ACNUDH, 2003: 5), por lo que debe estar subordinada al poder civil.

Por otra parte, como ente encargado del orden público, Carabineros de Chile es la institución llamada a actuar en su resguardo. Dicha situación lo ha puesto en un rol antagónico a las manifestaciones sociales, por cuanto en nuestro país existe una concepción de la protesta social que tiende a su criminalización, existiendo una tendencia a reprimir en vez de garantizar este derecho. En contraste, la Observación General 37 del Comité de Derechos Humanos de Naciones Unidas señala que «la imposición de cualquier restricción se debería guiar por el objetivo de facilitar el derecho, en vez de intentar limitarlo innecesaria y desproporcionadamente. Las restricciones no deben ser discriminatorias, comprometer la esencia del derecho o tener por objeto desalentar la participación en las reuniones o provocar un efecto disuasorio». ${ }^{9}$

En este sentido, dadas las graves violaciones a los derechos humanos y estándares internacionales, es conveniente analizar las directrices que el derecho internacional de los derechos humanos establece en la materia. A este respecto, el informe «Protesta y derechos humanos: Estándares sobre los derechos involucrados en la protesta social y las obligaciones que deben guiar la respuesta estatal», de la Relatoría Especial para la Libertad de Expresión de la Comisión Interamericana de Derechos Humanos, establece estándares que deben guiar la conducta de las fuerzas policiales en el contexto de la protesta social (CIDH, 2019:34). Al respecto, fija directrices sobre diferentes puntos, notables en consideración a la crisis que Chile atraviesa en la materia.

\section{Uso de la fuerza policial en el contexto de protestas}

Se ha establecido que el uso de la fuerza

se concibe como un recurso último que, limitado cualitativa y cuantitativamente, pretende impedir un hecho de mayor gravedad que el que provoca la reacción estatal. Dentro de ese marco caracterizado por la excepcionalidad, tanto la Comisión Interamericana de Derechos Humanos como la Corte IDH, han coincidido en que, para que el uso de la fuerza se encuentre justificado, se deberán satisfacer los principios de legalidad, absoluta necesidad y proporcionalidad (CIDH, 2019: 34).

9. «Observación General 37, relativa al derecho de reunión pacífica (artículo 21)», Comité de Derechos Humanos de Naciones Unidas, CCPR/C/GC/37, 17 de septiembre de 2020, disponible en https://undocs. org/es/CCPR/C/GC/37. 
$\mathrm{Al}$ respecto, la $\mathrm{CIDH}$ ha entendido el principio de legalidad como la obligación Estatal de «sancionar normas con jerarquía de ley, y en cumplimiento de las normas internacionales en la materia destinadas a regular la actuación de los agentes del orden en el cumplimiento de sus funciones», y además ha señalado que el uso de la fuerza «debe estar dirigido a lograr un objetivo legítimo, debiendo existir un marco regulatorio que contemple la forma de actuación en dicha situación» (CIDH, 2019: 42).

En relación con el principio de absoluta necesidad, apunta a la ejecución de medidas de seguridad ante hechos delictivos que pongan en riesgo el derecho a la vida o a la integridad personal de cualquier habitante, ante lo cual es necesario considerar otros medios menos lesivos que permitan la tutela de estos derechos, destacando que «no se puede acreditar este requisito cuando las personas no representan un peligro directo» (CIDH, 2019: 42).

Finalmente, en relación con la proporcionalidad, esta ha sido entendida como

la moderación en el actuar de los agentes del orden que procurará minimizar los daños y lesiones que pudieren resultar de su intervención, garantizando la inmediata asistencia a las personas afectadas y procurando informar a los familiares y allegados lo pertinente en el plazo más breve posible. Los agentes legitimados para hacer uso de la fuerza deben aplicar un criterio de uso diferenciado y progresivo de la fuerza, determinando el grado de cooperación, resistencia o agresión de parte del sujeto al cual se pretende intervenir y con ello, emplear tácticas de negociación, control o uso de la fuerza, según corresponda (CIDH, 2019: 43).

Además, el informe considera que el uso de la fuerza debe considerar que su ejercicio puede implicar un escalamiento en los niveles de tensión, debiendo actuar acorde a los principios de moderación, proporcionalidad y progresividad.

\section{Recomendaciones de organizaciones internacionales frente al estallido social}

Las graves y sistemáticas violaciones a los derechos humanos en el contexto de las masivas manifestaciones sociales llevaron a Chile a vivir la mayor crisis de derechos humanos desde el regreso a la democracia. En consecuencia, las miradas de diferentes organizaciones de derechos humanos, tanto nacionales como internacionales, se posaron en la realidad que se desarrollaba en Chile, específicamente, en el actuar de las Fuerzas de Orden y Seguridad, y de las autoridades encargadas jerárquica y políticamente de las mismas.

En este marco, la ONG Human Rights Watch (2019) recomendó a las autoridades chilenas una reforma urgente a la policía, proponiendo una serie de medidas, que hemos sistematizado en cuatro ejes programáticos:

Uso de la fuerza: i) Asegurar que existan mecanismos internos de control para investigar y sancionar abusos y el uso indebido de armas menos letales por parte de Ca- 
rabineros; ii) reformar el sistema de disciplina de Carabineros para que las decisiones disciplinarias las adopte una autoridad que no esté en la cadena directa de mando de la persona implicada, y cerciorarse de que el personal que trabaja en asuntos internos no tenga que trabajar con aquellos a quienes ha investigado o sancionado, ni quedar subordinado a ellos; iii) instalar cámaras en todas las áreas de todas las comisarías, tomando medidas para garantizar la privacidad de los detenidos, y establecer un sistema de almacenamiento de grabaciones que pueda ser empleado por autoridades judiciales o de otro tipo.

Control y transparencia: i) Suspender cualquier uso de perdigones — no solo durante manifestaciones - hasta que autoridades idóneas e independientes realicen un estudio adecuado de todos sus riesgos; ii) estudiar el uso de equipos menos letales alternativos que minimicen las lesiones; iii) reforzar el entrenamiento de todos los carabineros relacionado con armas menos letales para el control de manifestaciones, incluidas las Fuerzas Especiales, entre otras.

Protección de los derechos de manifestantes y detenidos en la protesta social: i) Revisar las facultades de detención por control de identidad de los carabineros, para que haya garantías contra el uso arbitrario de la facultad de interceptar y detener personas y que haya rendición de cuentas por su uso; ii) adoptar un protocolo junto con las autoridades de salud para que los detenidos sean sometidos a revisiones forenses independientes, que no se realicen frente a carabineros y ocurran a una distancia en la que no puedan ser escuchados; iii) hacer cumplir la prohibición vigente sobre desnudamiento de detenidos en protestas y sancionar a aquellos que continúen con esta práctica.

Condiciones de trabajo de funcionarios de Carabineros: Cerciorarse de que los carabineros cuenten con equipos de protección adecuados, tiempo de descanso y remuneración de horas extras.

Por su parte, Amnistía Internacional, en su informe «Ojos sobre Chile» (Amnistía Internacional, 2020), fue más allá en las críticas y recomendaciones a las autoridades chilenas. En primer orden, se refiere a la responsabilidad de mando que ostentan tanto los mandos estratégicos de Carabineros como el Poder Ejecutivo respecto a la institución policial. A este respecto, señala que

resulta difícil no pensar que la cadena de omisiones de los mandos estratégicos, como el general director, el subdirector o el director de Dioscar, lejos de ser fortuita, fue deliberada o como mínimo culposa por negligencia reiterada, extremos que deberán ser dilucidados por la justicia chilena. Esto significaría que dichas omisiones podrían haber sido parte de una política institucional, donde a toda costa debían dispersarse las manifestaciones, aunque eso supusiera asumir el daño a la integridad de las personas como un castigo y mal necesario para el restablecimiento del «orden público» (Amnistía Internacional, 2020: 107). 
Argumenta que las violaciones a los derechos humanos no podrían haberse desarrollado de forma generalizada si los mandos estratégicos hubieran tomado medidas destinadas a evitar y prevenir la concreción de las mismas, faltando a su posición de garantes.

Asimismo, afirma que

si bien Amnistía Internacional no analiza en este informe las posibles responsabilidades de otros actores más allá de Carabineros, considera que la falta de control ejercida sobre Carabineros por parte del Poder Ejecutivo exige que sean también deslindadas todas las responsabilidades políticas, administrativas o incluso penales hasta el máximo nivel posible, de todas aquellas personas que en su posición de garantes conocían o debieron conocer, si hubieran obrado con diligencia, la magnitud de las violaciones de derechos humanos, y que tenían la capacidad de evitarlas, y no obstante, no lo hicieron (Amnistía Internacional, 2020: 108).

En cuanto al acceso a la justicia, dispone que «Carabineros de Chile debe, de forma urgente, investigar internamente a todo el personal que pudiera ser sospechoso de violaciones de derechos humanos, y garantizar que ningún oficial, sobre el que pesan indicios de ello, permanezca en su puesto hasta que la investigación haya concluido y haya descartado de buena fe tal responsabilidad» (Amnistía Internacional, 2020: 108). Además, señala que las autoridades chilenas y la Fiscalía Nacional deben investigar las responsabilidades suscitadas dentro de la línea de mando de Carabineros, y que el Poder Judicial debe procesar a todas las personas que pudieran ser responsables de estas vulneraciones, garantizando el acceso a la justicia de las víctimas y sus familias, como también un debido proceso.

Finalmente, dadas las vulneraciones a los derechos humanos y a las normas internacionales sobre el uso de la fuerza, sumado a la naturaleza militar y estructura orgánica de la institución, Amnistía recomienda el desarrollo de una reforma estructural a Carabineros de Chile, para lo cual recomienda tener en consideración la propuesta entregada por la Comisión de Seguridad del Senado a finales de 2019.

Es fundamental que esta reforma no sea solo una modernización de algunos aspectos de detalle, sino que implique una reforma profunda a nivel normativo y cultural. Por un lado, se debe considerar el rol de Carabineros en una sociedad respetuosa de los derechos humanos; por el otro, su estructura equivalente a una rama de las Fuerzas Armadas y su relación con la comunidad y con el poder civil (Amnistía Internacional, 2020: 108). Sumado a ello, señala directrices tanto funcionales como sustantivas. Así, afirma que

durante el proceso de reforma de Carabineros, el Ejecutivo y el Legislativo deben convocar a un amplio diálogo social que incluya de forma activa la participación de la sociedad civil y de grupos históricamente discriminados como los pueblos indígenas, personas de la diversidad sexual y de géneros, personas migrantes, refugiadas 
y movimientos por los derechos de las mujeres y las niñas y feministas, entre otros» (Amnistía Internacional, 2020: 109).

En cuanto a medidas sustantivas, considera necesarias las siguientes reformas:

- Respeto y protección de los derechos humanos. En todas las tareas que desempeñe, Carabineros debe respetar, garantizar y promover de manera irrestricta los derechos humanos, velando permanentemente por su protección y difusión. Para ello, el área de derechos humanos de Carabineros debe tener competencias amplias y participar en la toma de decisiones a nivel estratégico y operativo de tal manera que su observancia sea integral.

- Auténtica subordinación al poder civil, con estricto apego al marco jurídico vigente, para lo cual propone la creación de un Ministerio de Seguridad Pública, independiente del Ministerio del Interior, que pueda ejercer un control efectivo y adecuado de la institución.

- Sistema de control, monitoreo, evaluación y de rendición de cuentas, que considere tanto el ámbito político institucional como el ciudadano. Para ello propone una reforma al órgano de control interno, cuyas funciones y nivel orgánico deben ser modificadas de tal manera que se garantice la autonomía de las investigaciones y su eficacia, además de revaluar los mecanismos de acceso a la información acerca de cómo opera Carabineros, en especial aquellos aspectos que son inaccesibles debido a un supuesto riesgo a la «seguridad nacional».

Por otro lado, como medidas que deben adoptarse de manera urgente, señala: i) prohibición del uso de los balines TEC Harseim y de cualquier otra munición de efecto múltiple y lesivo para funciones de orden público. ii) Elaboración de protocolos de control del orden público detallados, precisos, y acorde al derecho internacional en todos sus puntos; esto obligatoriamente conlleva la descripción precisa de cuándo y cómo el uso de la fuerza se hace necesario. Para la aprobación de dichos protocolos debería ser necesaria la aprobación de organismos expertos en la materia como el INDH y la Defensoría de la Niñez. iii) Revisión de los expedientes administrativos con el ánimo de garantizar que ninguna persona que haya cometido violaciones de derechos humanos permanezca en la institución.

\section{Propuestas reformistas: Acuerdo por la Seguridad Pública de 2018, Comisión de Seguridad del Senado de Chile y Consejo para la Reforma de Carabineros del Ministerio del Interior y Seguridad Pública}

En marzo de 2018, el presidente de la República Sebastián Piñera convocó al país a crear un acuerdo nacional por la seguridad pública. Para ello, el 6 de abril del mismo año se constituyó una mesa de trabajo integrada por actores de Gobierno y oposi- 
ción, parlamentarios, alcaldes, y representantes del Ministerio Público, del mundo civil y académico. ${ }^{10}$

Por su parte, el 26 de noviembre de 2019, la Comisión de Seguridad del Senado, a través de su presidente, convocó a un grupo transversal de académicos y expertos en políticas públicas de seguridad para desarrollar una propuesta de reforma a Carabineros de Chile. Para cumplir dicho cometido, se conformó la «Comisión de Reforma a Carabineros». ${ }^{11}$

Casi en paralelo, el 8 de diciembre de 2019 el Ministerio del Interior y Seguridad Pública convocó a distintos actores para conformar un Consejo para la Reforma de Carabineros de Chile, cuyo objetivo general fue complementar el proceso de modernización de policías llevado a cabo por el Gobierno. ${ }^{12}$

10. Asistieron a la convocatoria el ministro del Interior y Seguridad Pública, Andrés Chadwick P; el ministro de Justicia y Derechos Humanos, Hernán Larraín F.; el subsecretario del Interior, Rodrigo Ubilla M.; la subsecretaria de Prevención del Delito, Katherine Martorell A.; el exministro del Interior y Seguridad Pública y exdiputado, Jorge Burgos V.; los senadores Carolina Goic B., Felipe Harboe B., Juan Antonio Coloma C. y Andrés Allamand Z.; los diputados Matías Walker P., Javier Macaya D., Jorge Alessandri V., Andrés Molina M., José Pérez A. y Gonzalo Fuenzalida F.; los alcaldes de La Pintana, Claudia Pizarro P., de Santiago, Felipe Alessandri V., de Valparaíso, Jorge Sharp F. y de Pudahuel, Johnny Carrasco C.; el ex contralor general de la República, Ramiro Mendoza Z.; la directora de la Unidad Especializada Anticorrupción del Ministerio Público, Marta Herrera S.; el director ejecutivo de la Fundación Paz Ciudadana, Daniel Johnson R.; el académico de la Facultad de Derecho de la Universidad Diego Portales y presidente ejecutivo de Espacio Público, Mauricio Duce J.; el director del Centro de Seguridad Ciudadana de la Universidad Alberto Hurtado, Franz Vanderschueren, y el asesor del Ministro del Interior y Seguridad Pública Cristóbal Lira I.

11. La instancia está conformada por: los académicos Alejandra Luneke, de la Pontificia Universidad Católica; Guillermo Holzmann, de la Universidad Adolfo Ibáñez; Lucía Dammert, de la Universidad de Santiago de Chile; Mauricio Duce, de la Universidad Diego Portales; Franz Vanderschueren, de la Universidad Alberto Hurtado; Hugo Frühling, director del Instituto de Asuntos Públicos (INAP) de la Universidad de Chile; Daniel Johnson, director ejecutivo de la Fundación Paz Ciudadana; Cristóbal Weinborn, director del área Ciencias Policiales de Paz Ciudadana; Anamaría Silva, investigadora de Paz Ciudadana; Ruggero Cozzi, director del Instituto Libertad; Eduardo Vergara, director ejecutivo de la Fundación Chile 21; Jorge Burgos, exministro del Interior y Seguridad Pública; Antonio Frey, exsubsecretario de Prevención del Delito; Jorge Correa, exsubsecretario del Interior; Cristóbal Lira, alcalde de Lo Barnechea; los asesores parlamentarios Diego Pérez, Michael Heavey, Guillermo Miranda y Alejandro Vega; los senadores Felipe Harboe, Kenneth Pugh, José Miguel Insulza y Felipe Kast; y Ricardo Montero, secretario ejecutivo de la Comisión.

12. Este Consejo estuvo conformado por: Jorge Burgos Varela, exministro del Interior y Seguridad Pública y exdiputado; Jorge Correa Sutil, exsecretario de la Comisión Rettig y exsubsecretario del Interior; Hugo Dolmetsch Urra, expresidente de la Corte Suprema; Javier Etcheberry Celhay, miembro del Consejo Asesor Permanente para la Modernización del Estado, exministro de Transporte y Obras Públicas, exdirector del Servicio de Impuestos Internos; Daniel Johnson Rodríguez, director ejecutivo de Paz Ciudadana; Cristóbal Lira Ibáñez, alcalde de Lo Barnechea, exsubsecretario de Prevención del Delito; Catalina Mertz Kaiser, economista, ex directora ejecutiva de Paz Ciudadana; Marta Salcedo de 
A continuación, abordaremos los puntos en común y las diferencias entre las propuestas finales más relevantes emanadas de los tres documentos obtenidos producto de estos esfuerzos, a partir de las siguientes categorías:

- Transparencia y control civil de la institución.

- Formación y carrera de los integrantes de Carabineros de Chile.

- Funciones de la institución y eficacia en su funcionamiento.

- Estructura orgánica de Carabineros de Chile.

- Derechos humanos y democracia.

\section{Transparencia y control civil de la institución}

Los tres documentos entregan propuestas relativas al control del actuar policial. Sin embargo, el Acuerdo por la Seguridad Pública de 2018 únicamente plantea implementar una oficina de reclamos desde la ciudadanía. Por su parte, tanto la propuesta emanada del Senado como la de la instancia convocada por el Ministerio del Interior proponen una modificación en la institucionalidad que se encargue de la responsabilidad (accountability) tanto individual como organizacional. Sin embargo, la primera de las referidas contempla crear una Dirección de Asuntos Internos con atribuciones investigativas al interior de Carabineros, mientras que el Consejo para la Reforma entrega tal misión a un ente externo a la institución.

Por otro lado, tanto el Acuerdo por la Seguridad Pública de 2018 como la Comisión de Reforma a Carabineros consideran abordar el tópico de la sujeción de la institución al poder civil, relevando la importancia del control sobre la normativa interna que posee Carabineros.

A su vez, el Acuerdo por la Seguridad Pública y el Consejo para la Reforma proponen abordar la transparencia financiera delimitando los gastos reservados de la institución y revisando la necesidad de una rendición de cuentas sistemática.

Por otra parte, en lo que respecta a la inclusión de la sociedad civil, la propuesta emanada del Senado contempla su incorporación en lo relativo a propuestas de diseño, mientras que la propuesta del Consejo para la Reforma plantea fortalecer los Consejos Comunales de Seguridad Pública, para que se constituyan como instancias reales para que la comunidad y las autoridades locales coproducir seguridad con sus propias organizaciones en sus respectivos municipios.

\footnotetext{
la Fuente, coronel retirado de Carabineros de Chile; María Luisa Sepúlveda Edwards, presidenta del Museo de la Memoria y los Derechos Humanos, ex secretaria ejecutiva de la Vicaria de la Solidaridad; Franz Vanderschueren, académico de la Universidad Alberto Hurtado; y Cristóbal Weinborn de la Calle, director de área de Ciencias Policiales de Fundación Paz Ciudadana.
} 
Por último, el Acuerdo por la Seguridad Pública es el único que propone adecuar el catálogo de delitos de competencia de la justicia militar con el propósito de reducirlo conforme a la jurisprudencia de la Corte Suprema, orientándose progresivamente a que dicha magistratura no conozca causas por delitos o faltas en que las víctimas sean civiles, una necesidad que desde la sociedad civil se ha venido destacando desde hace un buen tiempo.

En general, las medidas propuestas tienden a radicar la fiscalización principalmente en el Poder Ejecutivo, sin considerar a organismos cuyo mandato especial es proteger los derechos humanos, como el Instituto Nacional de Derechos Humanos o la Defensoría de la Niñez, por nombrar solo algunos. Este es un punto no menor, pues desde un punto de vista histórico, cada vez que en los países de América Latina se han perpetrado masivas vulneraciones a los derechos humanos de la población civil, aquello ha sido producto de una política estatal. Por ende, en el contexto de la región no es garantía suficiente de control civil al actuar policial el rendir cuentas a la autoridad gubernamental de paso, y debería avanzarse hacia un sistema de control híbrido, que también otorgue potestades de control a, por ejemplo, un ombudsman, siempre teniendo a la vista evitar la dispersión de instituciones fiscalizadoras, avanzando hacia un sistema que evite un cruce de funciones.

Por otra parte, no se considera problematización alguna de los registros audiovisuales que obtienen los funcionarios policiales desde cámaras corporales, tema que debiera estar regulado vía ley de la República al menos en lo que respecta a su acceso por parte del órgano controlador. Ahora bien, son valorables las mejoras en materia de responsabilidad. Sin embargo, no basta con que se le de publicidad a los protocolos de uso de la fuerza, sino que estos deben ser revisados de manera transversal y actualizados conforme a los estándares internacionales.

\section{Formación y carrera de los integrantes de Carabineros de Chile}

En cuanto a este eje, los proyectos en análisis apuntan a la profesionalización del proceso formativo y a la inclusión de profesionales ya formados a la institución, resultando destacable la intención de establecer nexos con el mundo civil. En efecto, el Acuerdo por la Seguridad Pública propone la aprobación — por parte de la autoridad civil— de los perfiles profesionales de la institución (propuesta 38), y el sometimiento de las escuelas de formación de oficiales a los procesos de acreditación institucional de la Comisión Nacional de Acreditación (propuesta 39). Por su parte, la Comisión de Seguridad del Senado apunta a integrar a profesionales civiles especializados en educación y docencia, así como a permitir el ingreso externo de profesionales en distintos estadios de la carrera funcionaria. En cuanto al Consejo para la reforma de Carabineros desarrollado por el Ministerio del Interior y Seguridad Pública, propone elaborar un plan estratégico educacional, en el que se aborde el perfil de ingreso y de 
egreso, las competencias y habilidades que se busca desarrollar, los contenidos que se impartirán como parte de la formación (donde exista un modelo pedagógico atingente a la formación policial que cuente con un enfoque transversal de respeto a los derechos humanos), y un plan de monitoreo que considere a todos los planteles que forman parte del área de formación de Carabineros de Chile.

En lo referente al ingreso a la institución y sus diferentes escalafones, la Comisión de Seguridad del Senado propone establecer un sistema de reclutamiento de múltiples entradas, en el que el ascenso se realice de acuerdo con el mérito. Por su parte, aunque el Consejo para la Reforma desarrollado por el Ministerio del Interior problematiza sobre la diferenciación entre Esfocar y Escar, solo apunta a perfeccionar el sistema, mientras que el Acuerdo por la Seguridad Pública no se refiere a este punto. A este respecto, es crítico que los proyectos no se ocupen de los inconvenientes desarrollados a propósito de la existencia de dos escalafones diferentes, sujetos a mecanismos de ingreso diferenciados. Resulta imprescindible un escalafón único, que democratice la institución de modo que la carrera funcionaria dependa únicamente de la trayectoria y no de los medios de cada uniformado al momento de ingresar a la escuela.

En referencia a carrera funcionaria, la Comisión de Seguridad del Senado postula diseñar un nuevo sistema de incentivos para fomentar el aumento de los años de servicio y revisar la experiencia comparada para determinar la cantidad óptima de años para poder optar al retiro. En otro orden, el Acuerdo por la Seguridad Pública propone la ampliación para ambas policías de los plazos de permanencia de sus dotaciones en las funciones asignadas (propuesta 63), entre otras ideas, propuesta que no parece del todo pacífica, por cuanto parte de la doctrina ha señalado que mientras más tiempo se mantengan los funcionarios en un mismo entorno, resulta más factible la captura de sus funciones.

Finalmente, en lo referente a formación en derechos humanos, aunque la Comisión de Seguridad del Senado los menciona como principio inspirador del documento, llama profundamente la atención que no se incluya explícitamente en el ítem referido a la formación de los funcionarios, ya que es central pasar de capacitaciones esporádicas a una formación obligatoria e integral. Así, se habla de un enfoque general, pero no se establecen comisiones concretas ni instituciones encargadas de desarrollar este proceso. En paralelo, la instancia convocada por el Ministerio del Interior apunta a incluir los instrumentos internacionales de derechos humanos y de la normativa nacional de manera explícita en los programas de formación, en lo que sea pertinente para cada uno de los escalafones, verificando que estos tengan consistencia y comunicabilidad con los demás ramos que conforman la formación. Esta inclusión resulta valorable y destacable; no obstante, si bien es necesario que exista un enfoque transversal de respeto a los derechos humanos, existe la necesidad urgente de una formación en materias grupos vulnerables. 


\section{Funciones de la institución y eficacia en su funcionamiento}

En relación con este ámbito, las propuestas giran en torno a la determinación de las funciones que debe desarrollar la institución, sumado a la diferenciación y coordinación de Carabineros con otras instituciones.

Respecto al primer punto, la Comisión de Seguridad del Senado propone identificar las funciones principales que Carabineros debiera cumplir, priorizando la prevención del delito, el orden público, la investigación criminal residual, la inteligencia, el tránsito y seguridad vial, las fronteras, y emergencias, en adición a que Carabineros prescinda de aquellas funciones accesorias administrativas y operativas que no guardan relación con sus funciones principales, como notificaciones, denuncias, determinación de estándares y fiscalización de seguridad privada, entre otros. Por su parte, el Consejo para la Reforma de Carabineros propone principalmente establecer mecanismos de priorización para la ejecución de las funciones policiales en materia de control, prevención e investigación de delitos y alteraciones al orden público y generar sistemas de incentivos y fiscalización para el uso adecuado de los recursos en la institución; no obstante, en este apartado las propuestas parecen bastante insuficientes en lo que respecta a la especificación de las funciones de la institución, dado que las funciones de control, prevención e investigación se mantienen radicadas en Carabineros.

Desde otra perspectiva, en referencia a la relación de Carabineros de Chile con otras instituciones con vocación policial, tanto el Acuerdo por la Seguridad Pública (propuesta 1) como la Comisión de Seguridad del Senado apuntan a la radicación preferente de la función preventiva en la institución de Carabineros y a la radicación de la función investigativa en la Policía de Investigaciones, pues en la actualidad dicha frontera se ha confundido en más de una ocasión, lo que ha generado roces entre organismos.

Además, el Acuerdo por la Seguridad Pública postula crear un sistema integrado entre Carabineros, Policía de Investigaciones, fiscalías regionales y el Centro Estratégico de Análisis del Delito de la Subsecretaría de Prevención del Delito, para permitir un uso descentralizado y eficiente de la información (propuesta 59), entre otras proposiciones. Respecto a ello, parece problemático poner al Ministerio Público en un sistema en igualdad de condiciones con Carabineros, idea que si bien pretende facilitar la coordinación en las funciones, puede generar un enfoque confuso. En este sentido, es recomendable pensar un sistema coordinado que no ponga en riesgo la jerarquía de funciones y el carácter auxiliar que tienen las policías frente al ente persecutor.

A modo de crítica, no se aborda el tema de la jornada laboral de los funcionarios, que en muchos casos ha sido denunciada por el exceso de cansancio que genera. Igualmente, resulta inquietante que en estas propuestas no se evalúe la posibilidad 
de una refundación de ambas policías, centrándose solamente en perfeccionar el sistema actual, así como que nada se mencione a propósito del consumo de drogas y alcohol por parte de los funcionarios, cuestión que ha sido denunciada públicamente de forma reiterada.

\section{Estructura orgánica de Carabineros de Chile}

En este apartado, el Acuerdo por la Seguridad Pública propone otorgar a la Subsecretaría del Interior las facultades y atribuciones necesarias para ejercer un eficaz control presupuestario sobre las inversiones y gastos de las Fuerzas de Orden y Seguridad Pública (propuesta 14), modificar el artículo 4 de la Ley Orgánica Constitucional de Carabineros de Chile, haciéndolo concordante con lo establecido en el artículo 83 del inciso tercero de la Constitución, que señala que la Fiscalía «podrá impartir órdenes directas a las Fuerzas de Orden y Seguridad Pública» durante la investigación (propuesta 24); revisar y actualizar los criterios para la promoción y ascenso del personal de las Fuerzas de Orden y Seguridad contenidos en sus respectivas leyes orgánicas (propuesta 45); y establecer por ley la constitución del Alto Mando policial (propuesta 48), entre otras propuestas.

Respecto a este acápite, cabe señalar que existe una difusa diferenciación entre las funciones de la nueva Subsecretaría del Interior y Seguridad Pública y la Subsecretaría de Prevención del Delito. Así, la propuesta de radicar el control presupuestario de Carabineros en la Subsecretaría del Interior genera un cruce de funciones con la segunda.

Por otro lado, se valora el designio de evaluar los criterios de ascenso y de establecer por ley la constitución del Alto Mando policial; sin embargo, es necesario precisar los criterios que conforman el mérito necesario para acceder a dichas posiciones, y que aquello también sea parte de una deliberación democrática y con criterios de publicidad.

En otro orden de ideas, tanto la Comisión de Seguridad del Senado como el Consejo para la Reforma de Carabineros proponen revisar la estructura orgánica del Ministerio del Interior y Seguridad Pública y evaluar la creación de un Ministerio de Seguridad Pública que permita separar las funciones de coordinación política de las funciones de seguridad, cuya orgánica, presupuesto y atribuciones sean coherentes con el carácter transversal de las políticas de seguridad y su foco preventivo. Además, la propuesta del Senado apunta a un rol activo del Congreso Nacional, ampliando sus atribuciones de fiscalización en materia presupuestaria y de evaluación policial.

$\mathrm{Al}$ respecto, consideramos conveniente evaluar la creación de un ministerio especializado en la materia; no obstante, ello conlleva hacer una revisión de las funciones radicadas en las subsecretarías, sumado a una coordinación con el Ministerio Público y demás instituciones involucradas en el ius puniendi. Además, la creación de este 
ministerio puede resultar riesgosa en el actual contexto político-social, en el que se han justificado violaciones y vulneraciones a los derechos de las personas en virtud del orden público.

Finalmente, el Consejo para la Reforma de Carabineros propone coordinar el trabajo de las instituciones policiales, y de estas con otras instituciones públicas y privadas que tienen funciones policiales o fiscalizadoras, especialmente a nivel de control fronterizo. En referencia a ello, cabe advertir: i) el riesgo de incluir actores privados en dicha función, desnaturalizando completamente la función del ius puniendi estatal, y además, ii) resulta fundamental no perder de vista la subordinación jerárquica de la policía al Ministerio Público, cuestión que problematizamos previamente.

\section{Derechos humanos y democracia}

En este punto llama la atención el abordaje de los tres documentos sobre la inequidad de género y los problemas de una institución eminentemente patriarcal. El Acuerdo por la Seguridad Pública considera realizar los cambios necesarios en la infraestructura de cuarteles y dependencias disponibles, mecanismos para fomentar la igualdad de oportunidades de ascenso y acceso a los cargos superiores a las mujeres de las instituciones policiales, además de apoyo a la maternidad y el establecimiento de un sistema de denuncias por acoso sexual.

En la misma línea, la Comisión de Reforma a Carabineros aborda el problema del ingreso inequitativo para las mujeres, de las posibilidades de acceso a los altos grados y de la maternidad. Además, propone crear una Dirección de Género, con el fin de transversalizar la perspectiva de género en la institución.

Por su parte, el Consejo para la Reforma de Carabineros plantea garantizar la igualdad de oportunidades de ascenso y acceso a los cargos superiores.

Respecto a esta temática, llama positivamente la atención la inclusión de criterios de inclusión femenina en la institución. Sin embargo, una perspectiva de género no es solo cualitativa, sino que cuantitativa. En ese sentido, el apoyo a la maternidad debería ser equivalente al apoyo a la paternidad, pues ignorar el rol paterno en la crianza de los hijos solo reproduce el rol sexista asignado por el patriarcado a las mujeres.

En cuanto a las diferencias, vemos que únicamente el Acuerdo por la Seguridad Pública plantea eliminar el carácter secreto de las plantas y dotaciones de Carabineros de Chile. Por otro lado, y en lo que respecta a la entrega de información en materia de derechos humanos, la Comisión de Reforma a Carabineros propone generar protocolos estrictos de entrega de información que facilite el trabajo del Instituto Nacional de Derechos Humanos, la elaboración un informe anual sobre actuaciones policiales y derechos humanos, auditables por organismos externos especializados, y generar un sistema de intervención focalizado de las unidades policiales y comisarías que registren denuncias de abuso policial y violación de derechos humanos. 
Por último, en materia de capacitación, el Consejo para la Reforma de Carabineros plantea que las reparticiones de Carabineros de Chile destinadas a la formación y al resguardo de los derechos humanos elaboren en forma conjunta programas formativos que entreguen conocimientos y competencias para el desarrollo de las funciones de diálogo y negociación.

Cabe subrayar que en ninguna de las propuestas se hace mención a uno de los elementos más problemáticos del actuar policial desde, al menos, noviembre de 2019 a la fecha: la necesidad de revisión de los protocolos de uso de la fuerza. Pese a que estos fueron actualizados recientemente, se requiere que la normativa que rija a Carabineros en contextos de uso de la fuerza sea reformulada tanto en su mérito mismo como en lo referido al lugar que ocupará dentro de la escala del ordenamiento jurídico, y que, por supuesto, se ajuste a los estándares internacionales que existen en la materia.

Asimismo, no se menciona el establecimiento y reforzamiento de sanciones internas o externas a funcionarios que vulneren los derechos humanos, ni se hace referencia a la reestructuración o fortalecimiento de la unidad de derechos humanos, cuestiones que son a todas luces centrales en los llamados de la sociedad civil a refundar la institución.

\section{Conclusiones y recomendaciones}

Tal como se ha dado cuenta a lo largo de este artículo, la crisis de derechos humanos de Carabineros de Chile tiene raíces profundas, que se correlacionan con su carácter militarizado, hermético y atomizado respecto del poder civil.

El desarrollo de la dictadura militar trajo consigo una profundización en la militarización de la fuerza policial, situación que en suma a aspiraciones de autonomía y disminución del control ciudadano sobre la institución, iniciaron una pugna con consecuencias negativas hasta hoy. Pese a que la institución está orgánicamente sometida al orden civil, se encuentra ubicada en un ministerio de carácter eminentemente político, que no distingue entre orden y seguridad pública, además de persistir con dinámicas de transparencia, control institucional y observancia en derechos humanos que no concuerdan con el paradigma y las necesidades de la sociedad actual.

Lo anterior puede ser una manifestación más de la incompleta recomposición de unas saludables y constructivas relaciones cívico-militares, que se han traducido en otras fricciones, dificultades o conflictos abiertos de similar naturaleza en distintas ramas de las Fuerzas Armadas, que pueden también estar en cierto modo explicadas por el recelo al escrutinio público y el control civil y político de parte del mundo uniformado, y de rastros de parte del mundo político del trauma que el uso de la fuerza por parte del mundo militar significó para la democracia y sus instituciones.

En los últimos años se han llevado a cabo una serie de esfuerzos por orientar a 
Carabineros de Chile hacia las necesidades del país, tratando de transformar a la institución en una policía moderna y, recientemente, acorde a un Estado democrático y a los estándares internacionales de derechos humanos existentes al efecto.

Así, a lo largo de este artículo, pudimos ver distintas propuestas de reforma a la institución, surgidas desde 2018 en adelante, y en distintas instancias del aparato estatal. En general, ninguna plantea la posibilidad de una refundación total de la policía en el país. Sin embargo, existen planteamientos de hondo calado, como los señalados por Human Rights Watch o Amnistía Internacional en sus informes ya citados. Esta última organización recomienda una reforma estructural a la institución de Carabineros, sugiriendo considerar la propuesta de la Comisión de Seguridad del Senado chileno a finales de 2019. Este informe evidencia la necesidad de un mayor control de la institución por parte del poder civil, así como cambios urgentes que aseguren el apego irrestricto al derecho internacional de los derechos humanos. Así, tal documento otorga una base sólida, como punto de partida, en lo que se refiere a transparencia y control civil de la institución, formación y carrera de los integrantes de Carabineros de Chile, funciones y eficacia en su funcionamiento, estructura orgánica, derechos humanos y democracia.

No obstante lo anterior, en definitiva las dinámicas y prácticas vulneratorias denunciadas masivamente a propósito del estallido social se encuentran arraigadas con fuerza en Carabineros de Chile, y dan cuenta de deficiencias y lógicas en su funcionamiento que han formado parte de la institución por décadas, frente a las cuales los procesos de reforma han resultado infructuosos.

El motivo por el cual estas reformas no han dado frutos radica, por una parte, en el carácter de mera reforma y modernización, considerando que Carabineros necesita un cambio de paradigma en cuanto a su modelo de policía, en miras a concordar con el orden democrático e institucional que Chile actualmente exige y necesita, con respeto y observancia a los estándares internacionales que el derecho internacional de los derechos humanos dicta en la materia.

Por lo anterior, con el objeto de evitar el desarrollo de reformas superficiales e infructuosas, el método que se posiciona como efectivo a fin de evitar la repetición de las prácticas denunciadas y lograr una correspondencia efectiva de Carabineros con el orden civil, consiste en una intervención que cambie totalmente el paradigma que caracteriza a la institución, erigiendo con ello un nuevo modelo de policía para el país. Para ello, es necesario adecuar a las Fuerzas de Orden y Seguridad a los estándares internacionales referidos, tomando la plantilla actual de efectivos policiales y reclutando a aquellos que posean una hoja de vida acorde con los nuevos estándares, generando un nuevo cuerpo policial que incluya los siguientes ejes, no taxativos: i) sujeción a estándares del derecho internacional de los derechos humanos; ii) transparencia y fiscalización; iii) desmilitarización; iv) formación; v) orgánica. 
Sujeción a estándares del derecho internacional de los derechos humanos: Este punto es clave en cuanto a la concepción de una nueva policía. Por ello, su influencia debe ser transversal a todos los ejes y elementos que compongan la institución, para lo cual se propone que, al momento de regular temáticas como formación funcionaria, sanciones, protocolos y estándares de uso de la fuerza, relación con la comunidad, entre otros, se cuente con la colaboración de organismos expertos en la materia, como el Instituto Nacional de Derechos Humanos o la Defensoría de la Niñez, en miras a lograr una real sujeción de la institución a estándares propios de un país democrático y respetuoso de los derechos humanos.

Transparencia, control y fiscalización: Este eje se ha posicionado como uno de los más conflictivos desde el estallido social, dada la opacidad de la institución $\mathrm{y}$ ausencia de transparencia respecto a su funcionamiento y control interno. Por ello, siguiendo las recomendaciones presentadas por Amnistía Internacional, en un nuevo modelo de policía deben asegurarse mecanismos efectivos de transparencia que permitan tener acceso a la información acerca de cómo opera la institución, de forma transversal, ya sea en asuntos orgánicos, funcionarios, financiamiento, sanciones, etcétera.

Asimismo, en el ámbito de control debe considerarse un sistema de control, monitoreo, evaluación y rendición de cuentas, que considere tanto el ámbito político institucional como el ámbito ciudadano. Por un lado, el órgano de control interno de la institución debe contar con funciones y un nivel orgánico tal que garantice la autonomía en el ejercicio de su control, investigación y sanciones. Por otro lado, debe existir un organismo de control y fiscalización por parte de la ciudadanía. Para ello, es necesario constituir en el menor plazo posible una oficina o comité ad hoc de control policial, compuesto por expertas y expertos civiles independientes, para supervisar los procedimientos de respuesta a las denuncias de infracciones, abusos graves cometidos por efectivos policiales, resguardar el apego a los estándares de derechos humanos y los protocolos para uso de la fuerza, además de proponer mecanismos para avanzar hacia un programa de reparación integral hacia las víctimas de violaciones de derechos humanos durante el estallido social, en conjunto a un programa de garantías de no repetición.

En esta línea, debe apuntarse a la creación de una Oficina Independiente de Control Policial, en miras al modelo de la IOPC de Inglaterra y Gales, con una conformación paritaria y que en su integración exista, al menos, una especialista en género y derechos de las mujeres, designada por el Sernameg.

Sumado a lo anterior, se debe garantizar el correcto resguardo del registro audiovisual de todos los operativos policiales, otorgando pleno acceso a este registro al Ministerio Público y la Defensoría, así como a la Oficina Independiente de Control Policial. Además de la realización de examen de drogas sorpresa, con periodicidad, a toda la institución. 
Desmilitarización de la policía: En orden a lograr este fin, se debe sustraer a esta nueva policía del Código de Justicia Militar, debiendo estar sometida a su reglamentación interna en cuanto funcionarios y Código de Conducta, y a la justicia ordinaria ante la comisión de crímenes y delitos.

Por otro lado, debe apuntarse a este fin en áreas como formación, sanciones internas, jerarquía, trato entre funcionarios, control civil y ciudadano, etcétera.

Formación: La policía debe contar con una formación completa, profesionalizada y técnica, para lo cual se debe requerir de la participación de expertas y expertos en educación, tanto en la elaboración de las mallas curriculares como en la planta docente. En miras a ello, se propone contar con la participación de universidades públicas y organismos internacionales destinados al efecto, debiendo capacitarse a los funcionarios para un ejercicio de sus funciones específicas acorde a los nuevos estándares.

Asimismo, debe evitar replicarse el modelo de formación presente en la actualidad, en que se distingue entre oficiales y suboficiales, reemplazándolo por una escuela y escalafón único para la policía.

Los funcionarios que hoy forman parte de Carabineros de Chile, que cumplan con los requisitos en cuanto a buen comportamiento y posean una hoja de vida acorde, deben recibir cursos de formación y preparación para integrar esta nueva policía, adecuándose con los principios y estándares propios de esta, propendiendo a su constante perfeccionamiento profesional y adaptación a la nueva institución.

Orgánica y funcionarios: La composición orgánica de la policía debe dar cuenta de los ejes anteriormente mencionados, sustentando un modelo que permita un efectivo orden, control y transparencia, y sujeción a las entidades jerárquicamente superiores, con énfasis en el Ministerio Público.

Además, debe contemplar las necesidades especiales de la comunidad y la sociedad, requiriéndose la creación de unidades de atención primaria (receptoras de denuncias) especializadas e interdisciplinarias según usuarios: género, infancia, población indígena y población migrante.

Por otro lado, debe contarse con un enfoque de género, tanto en la incorporación de nuevos miembros a la institución como en el desarrollo de un proceso de articulación, integración y no discriminación en su funcionamiento interno, ya sea en el trato entre funcionarios o en temas administrativos, laborales, infraestructura, etcétera.

Finalmente, se debe articular una rotación permanente de policías integrantes de la policía fronteriza, para evitar la captura de las y los funcionarios, sumado a promover horarios de trabajo con una jornada que permita descansos adecuados para todo el personal policial.

A la fecha siguen sucediéndose instancias técnico-políticas para esta reforma: además de las ya mencionadas, el Comité Técnico Asesor de Derechos Humanos, creado el 22 de diciembre de 2019 por el Comité Interministerial de Derechos Hu- 
manos para «analizar y generar propuestas de implementación respecto de las recomendaciones sugeridas en el informe dado a conocer por Human Rights Watch», o la más reciente creación de la Unidad Coordinadora que colabora en las tareas de la Comisión de Reforma de Carabineros, instancia que data de octubre recién pasado. Pero la proliferación de estas instancias está lejos, todavía, de ser la respuesta.

Es por ello imprescindible hacer una prevención: no debe de perderse de vista que el otro motivo fundamental del fracaso del proceso aquí descrito lo constituye el desempeño de la política, más específicamente, la ausencia de convicción política para intervenir la institución, la seducción del discurso populista del punitivismo y la sistemática renuncia a la formulación de políticas públicas basadas en evidencia.

Han existido suficientes señales de los problemas estructurales en Carabineros de Chile, pero ha subsistido la tendencia a reformar la legislación mediante el recurso de emergencia (bajo la forma de las denominadas «agendas cortas antidelincuencia») que albergaban en su seno más discursos de temor o simplificación («buenos y malos», «decentes e indeseables») que focalización, eficiencia y rendición de cuentas. Otras veces se ha tratado solo de un irreflexivo eco a un clamor policial por mayores atribuciones sin un adecuado correlato de evidencia de su necesidad, razonabilidad o proporcionalidad (de lo cual es un ejemplo dramático las reformas a las facultades legales de la policía para proceder a controles de identidad de la población). Este comportamiento irresponsable es reciente e indesmentible, y debe llevar al legislador a un profundo examen de conciencia. La conciencia de sus errores en este plano puede ser un buen punto de partida para los desafíos por venir, cruzados por la expectativa amplia y urgente de una ciudadanía especialmente crítica y abiertamente escéptica.

\section{Referencias}

ACNUDH, Oficina del Alto Comisionado de las Naciones Unidas para los Derechos Humanos (2003). «Normativa y práctica de los derechos humanos para la Policía: Manual ampliado de derechos humanos para la Policía». HR/P/PT/5/Add.3. Disponible en https://bit.ly/3iRmwcO.

Amnistía Internacional (2020). «Ojos sobre Chile: Violencia policial y responsabilidad de mando durante el estallido social». AMR 22/3133/2020. Disponible en https://bit.ly/3zEYgBI.

CIDH, Comisión Interamericana de Derechos Humanos (2019). «Protesta y derechos humanos: Estándares sobre los derechos involucrados en la protesta social y las obligaciones que deben guiar la respuesta estatal». OEA/Ser.L/V/II, CIDH/RELE/ INF.22/19. Disponible en https://bit.ly/3wvvoLs.

Human Rights Watch (2019). «Chile: Llamado urgente a una reforma policial tras las protestas». Disponible en https://bit.ly/3kZgnOj. 


\section{Sobre los autores}

Luis Felipe Аввотt Matus es abogado. Licenciado en Ciencias Jurídicas y Sociales de la Universidad de Chile. Profesor del Departamento de Ciencias Penales de la Facultad de Derecho de la Universidad de Chile. Investigador asociado y subdirector del Centro de Derechos Humanos de la Universidad de Chile. Su correo electrónico es fabbott@derecho.uchile.cl. (ID https://orcid.org/oooo-0001-6208-325X.

Paz Pino Venegas es estudiante de la Facultad de Derecho de la Universidad de Chile. Ayudante de Derecho Constitucional y del Centro de Derechos Humanos de la Facultad de Derecho de la Universidad de Chile. Su correo electrónico es paz.pino@ derecho.uchile.cl. (D) https://orcid.org/0000-0002-6519-4462.

Renata Villamán Juica es abogada. Licenciada en Ciencias Jurídicas de la Universidad de Chile. Ayudante del Centro de Derechos Humanos de la Facultad de Derecho de la Universidad de Chile y miembro de la corporación de derechos humanos «Londres 38, Espacio de Memorias». Su correo electrónico es renata.villaman@gmail. com. (D) https://orcid.org/00oo-0002-8683-1838. 
El Anuario de Derechos Humanos es una publicación semestral de referencia y consulta en materia de derechos humanos y campos afines. Busca ser un espacio de discusión de los temas centrales en el ámbito nacional e internacional sobre derechos humanos. Es publicado desde 2005 por el Centro de Derechos Humanos de la Facultad de Derecho de la Universidad de Chile.

\author{
EDITORA \\ Claudia Iriarte Rivas \\ ciriarter@derecho.uchile.cl \\ SITIO WEB \\ anuariocdh.uchile.cl \\ CORREO ELECTRÓNICO \\ anuario-cdh@derecho.uchile.cl \\ LICENCIA DE ESTE ARTÍCULO \\ Creative Commons Atribución Compartir Igual 4.o Internacional
}

\author{
\% \\ La edición de textos, el diseño editorial \\ y la conversión a formatos electrónicos de este artículo \\ estuvieron a cargo de Tipográfica \\ (www.tipografica.io)
}

